\title{
A SIMPLIFIED MATRIX ANALYSIS APPROACH TO MULTI STOREY BUILDINGS INVOLVING A FRICTION DAMPER
}

Kamyar GHARRA ${ }^{1}$, Karen KHANLARI ${ }^{2 *}$, Jafar ASGARI ${ }^{3}$, Mohammad

\section{Abstract}

Damping through friction tends to be one of the most efficient methods to suppress damage to structures from earthquakes. Realizing robust structures is therefore highly dependent on designing for the dynamic forces of friction- damped structures and exploring their reliability against natural disasters. This paper presents a simplified matrix analysis algorithm for multi-storey friction- damped buildings. We have analyzed the behavior of friction- damped systems more accurately by modeling the master-slave degree of freedom of the joints. First, the formulation of the problem is discussed, and a condensed general equation is derived. Then, an end- to- end solution is proposed to find the responses of structures. The displacement response of each storey has been carried out in both condensed and non-condensed general equations, and the results clearly show the accuracy of the proposed method. The numerical analysis and the results of the simulation of various friction-damped structures depicts the proposed approach consists with the commercial finite element method and is applicable for the analysis various types of structures. It is noted that the acceleration and displacement responses of the structures investigated under the proposed method and the traditional finite element method are so consistent that only a 1.5\% difference is observed. Moreover, as a result of the proper allocation of degrees of freedom during the analysis, this method yields a reduction in computational costs especially in large buildings.

\section{Address}

1 Dept. of Civil Engineering, Faculty of Technology and Engineering, Central Tehran Branch, Islamic Azad University, Tehran, Iran

2 Dept. of Civil Engineering, Faculty of Technology and Engineering, Central Tehran Branch, Islamic Azad University, Tehran, Iran

3 Dept. of Civil Engineering, Faculty of Technology and Engineering, Central Tehran Branch, Islamic Azad University, Tehran, Iran

* Corresponding author: kar.khanlari@iauctb.ac.ir karen.khanlari@gmail.com

\section{Key words}

- Analytical modeling,

- Friction damper,

- Matrix analysis,

- Master-slave modeling,

- Multi degree of freedom.
Structures in any geographic location may be subjected to natural hazards such as earthquakes. Although the inherent phenomena are inevitable, the impacts of earthquakes, and the cost of such disasters can be reduced if seismic control approaches are implemented within structures. In this way, analyzing soil and investigating total displacement formulations in the frequency domain has been suggested for structures with an embedded elastic foundation (Králik, 2010). Another approach used semi-active base isolation control systems (Dadkhah et al., 2017; Ounis et al., 2013)

However, the avoidance of structural collapse alone is not sufficient because the costs of finishes, contents, and sensitive instrumen- tation can be high. In this way if a major portion of the seismic energy independent of the primary structure is dissipated mechanically, then the destructive effects can be reduced (Armali et al., 2019). With the emergence of friction dampers (Pall, 1996), it became economically feasible to significantly increase resistance to earthquakes, and damage control potential of a structure. In general, frictional equipment performs well against earthquakes in such a way that their response is independent of the loading range and frequency, as well as the number of loading cycles. Two major types of frictional dampers are linear and rotational and operate on the principle of a coulomb damping (Shaw, 1986). Due to a rectangular hysteretic loop of a friction damp- 
er, as long as a building is sufficiently elastic, it tends to settle back to its original positions after an earthquake. One of the main aspects of this kind of damper is the higher energy dissipation due to the large area under the friction damper curve (Pall, 2004) which has led to a need for fewer devices for a certain level of earthquake.

The use of a friction damper results in a higher protection level for buildings against earthquakes (Caudana, 2018). Friction dampers are one of the most efficient methods of dissipating seismic energy. It has been shown that the efficiency of the energy dissipation of wall friction dampers under far-field earthquakes was $118 \%$ higher than that under near-field ones (Nabid et al., 2019). In another study (Jarrahi et al., 2020), a rotational friction damper was investigated, and the modeling results showed $54 \%$ and $97 \%$ reductions in the maximum roof displacement and hysteresis energy, respectively. Recent researches (Sanghai et al., 2014) investigated five different damper location formats in SAP2000 based on the El Centro earthquake record. The results showed that the response of the structure i.e, the time period, storey displacement, drift, and acceleration could be reduced by using a friction damper. However, it was shown that the percentage of the dissipation of the energy input through link hysteretic behavior depended upon the location and the number of friction dampers. Ontiveros et al. (2017) presented a methodology to reduce the maximum displacement at the top of a structure and the maximum inter- storey drift using two objective functions. The results depicted a reduction of about 66 percent of the parameters mentioned. Wu (2005) and Sarjou (2017) discussed an improved friction damper, which is used in cross bracings with the difference that its central core was T-shaped. Four accelerograms of the Kobe, Naghan, Tabas and SanFernando earthquakes were used for a dynamic time-history analysis of the frames simulated in SAP2000. It was concluded that the improved friction damper could outperform in severe earthquakes such as Kobe and Tabas. The optimization of force as well as the position of the friction damper was addressed in Miguel et al. (2016). The results proved that the proposed method was able to reduce the inter -storey drift of a shear of a building by more than $65 \%$ and the maximum displacement at the top of the tower by approximately $55 \%$ with only three friction dampers. Since the above methods could not be used as practical cases because of the computational complexity, Nabid et al. (2017) developed a more effective method in which they introduced an empirical design equation that maximized the energy dissipation of a wall friction damper. In a recent study Nabid et al. (2019) presented a low computational method in which the computational costs were reduced up to 300 times compared to non-linear dynamic analyses.

All the above research assumed a spring-mass system in their processes. It must have assumed a very large degree of stiffness in their models, for springs in the non-sliding mode and zero stiffness in the sliding mode. As a result of this assumption, the stiffness of the element and deformation in the structural element would be different. This paper focuses on the most important aspects of friction damper modeling, i.e., a is frame analysis based on the behavior of each joint within the structure. In this way, we propose an analytical matrix analysis method based on the master-slave modeling of joints. The main objective of this paper is to provide a more accurate practical approach for the dynamic analysis of friction -damped structures.

\section{MATHEMATICAL FORMULATION}

\subsection{General Equation in a MDOF system}

We start our analysis by modeling a friction joint as a multi-degree of freedom (MDOF) system. As can be seen in Figure 1, in addition to two axial degrees of freedom (DOF) for friction ( $i$ and $j$ ), we also consider a vertical DOF $(s)$ and a rotational DOF $(r)$. This is because the joints do not disconnect and work together. The following assumptions are considered: (a) the natural frequency of the friction -damped structure is constant; (b) the general equation is nonlinear due to the friction; (c) the end point is different from the starting point; (d) If the bracing force is less than the friction force, the slip behavior does not occur, and the system acts as a braced frame.

Fig. 1 Friction joints in a MDOF frame

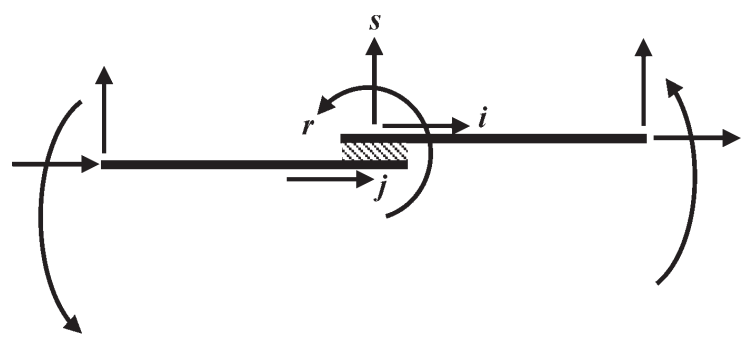

The general equation in the MDOF's structure can be written as Eq. (1):

$$
\boldsymbol{M} \ddot{x}(t)+\boldsymbol{C} \dot{x}(t)+\boldsymbol{K} x(t)=f(t)
$$

$\boldsymbol{M}$ is the mass matrix with a size of ; $\boldsymbol{C}$ is the damping matrix with a size of NDOF $\times$ NDOF; NDOF; $\boldsymbol{K}$ is the stiffness matrix with a size of ; $\ddot{x}(t)$ is the number of DOFs; $\dot{x}(t)$ is the acceleration response vector; $x(t)$ is the velocity response vector; is the displacement response vector; and $f(t)$ is the external force vector.

\subsection{General equation based on master-slave condensation}

Since actual industrial, structures are generally represented by very large finite element models, it is usually not possible to efficiently solve the set of non-linear Eq. (1) when consists of the harmonic components of all the DOFs. Generally, it may be necessary to reduce a finite element model to a smaller size. In our previous research work (Khanlari, 2018), it was shown that condensation is a highly efficient method for a reducing model and saving computational costs. This paper therefore presents a practical low complexity algorithm, which is based on the reduced order DOF of a system. Therefore, using the mentioned theory, an accurate analysis of a structure's behavior is possible through the direct modeling of each joint of a structure. In this case, the general equation can be partitioned into master (index: $m$ ) and slave (index: $s$ ) ones to form Eq. (2).

$$
\left[\begin{array}{cc}
M_{m m} & O_{s m} \\
O_{s m} & O_{s s}
\end{array}\right]\left[\begin{array}{c}
\ddot{x}_{m} \\
\ddot{x}_{s}
\end{array}\right]+\left[\begin{array}{cc}
K_{m m} & K_{m s} \\
K_{s m} & K_{s S}
\end{array}\right]\left[\begin{array}{c}
x_{m} \\
x_{s}
\end{array}\right]=\left[\begin{array}{c}
f_{m} \\
f_{s}
\end{array}\right]
$$

$x_{m}$ is the displacement vector of the master DOFs; $\mathrm{x}_{\mathrm{s}}$ is the displacement vector of the slave DOFs; $K_{m m} \cdot K_{m s} \cdot K_{s m}$ and $K_{s s}$ are partitions of the stiffness matrix; $M_{m m}$ is the main partition of the mass matrix; $O_{m s} \cdot O_{s m}$ and $O_{s s}$ are null partitions of the mass matrix; $f_{m}$ is the external force vector on the master DOFs; and $f_{s}$ is the external force vector on the slave DOFs. By expanding of Eq. (2) we will have Eq. (3):

$$
\begin{gathered}
M_{m m} \ddot{x}_{m}+K_{m m} x_{m}+K_{m s} x_{s}=f_{m} \\
K_{s m} x_{m}+K_{s s} x_{s}=f_{s} \Rightarrow x_{s}=K_{s s}{ }^{-1}\left(f_{s}-K_{s m} x_{m}\right)
\end{gathered}
$$

By applying the results of Eq. (3b) into Eq. (3a), we will obtain Eq. (4):

$$
M_{m m} \ddot{x}_{m}+\left(K_{m m}-K_{m s} K_{s s}{ }^{-1} K_{s m}\right) x_{m}=f_{m}-K_{m s} K_{s s}^{-1} f_{s}
$$


So, in comparing Eq. (4) with the traditional general equation, we can extract the condensed or reduced mass and stiffness matrices as Eq. (5):

$$
\begin{gathered}
\boldsymbol{M}^{*}=M_{m m} \\
\boldsymbol{K}^{*}=K_{m m}-K_{m s} K_{s s}{ }^{-1} K_{s m}
\end{gathered}
$$

The reduced external force vector is defined as Eq. (6):

$$
\boldsymbol{f}^{*}=f_{m}-K_{m s} K_{s s}^{-1} f_{s}
$$

The general equation of a system can then be redefined based on the master DOFs as Eq. (7):

$$
\boldsymbol{M}^{*} \ddot{x}_{m}+\boldsymbol{K}^{*} x_{m}=f^{*}
$$

In the condensed general equation, the external force vector of the master DOFs, $f_{m}$, is actually the seismic force (i.e., the earthquake) In the same way, the vector of the forces related to the slave DOFs, $f_{s}$, is the vector in which the frictional forces are placed. To achieve the velocity of the slave DOFs, $\dot{x}$, by considering ( $3 \mathrm{~b}$ ), we can obtain the differentiation of this vector as Eq. (8):

$$
\begin{gathered}
\boldsymbol{x}_{\boldsymbol{s}}=K_{s s}{ }^{-1} f_{s}-K_{s s}{ }^{-1} K_{s m} x_{m} \\
\frac{d}{d t} \boldsymbol{x}_{s}=K_{s s}{ }^{-1} \frac{d}{d t} f_{s}-K_{s s}{ }^{-1} K_{s m} \frac{d}{d t} x_{m}
\end{gathered}
$$

Hence, we can consider that the vector of the frictional forces of slave DOFs is equal to the zero vector $\left(\frac{d}{d t} f_{s} \cong\{0\}\right)$.

We can therefore approximately redefine the velocity vector of the slave DOFs as Eq. (9):

$$
\dot{x}_{\boldsymbol{s}} \cong-K_{s s}{ }^{-1} K_{s m} \dot{x}_{m}
$$

Eq. (9) lets us define the velocity of the slave DOFs in the terms of the master DOFs. In fact, through this important relation we can solve the condensed general equation in a lower degree. To obtain the actual general equation of a structure that explains the behavior of each member, we need to determine the system stiffness matrix as defined in Eq. (10):

$$
\boldsymbol{K}=\sum_{i=1}^{N E L} T_{i}^{T} R_{i}^{T} k_{i} R_{i} T_{i}
$$

$K_{m m}, K_{m s}, K_{s s}, K_{s m}$ and $K_{s s}$ are defined as follows:

$$
\begin{gathered}
K_{m m}=\operatorname{submatrix}\left(\boldsymbol{K}, 1, n_{\text {story }}, 1, n_{\text {story }}\right) \\
K_{m s}=\operatorname{submatrix}\left(\boldsymbol{K}, 1, n_{\text {story }}, n_{\text {story }}+1, D O F\right) \\
K_{\text {sm }}=\operatorname{submatrix}\left(\boldsymbol{K}, n_{\text {story }}+1, D O F, 1, n_{\text {story }}\right) \\
K_{\text {sS }}=\operatorname{submatrix}\left(\boldsymbol{K}, n_{\text {story }}+1, D O F, n_{\text {story }}+1, D O F\right)
\end{gathered}
$$

In Eq. (10), $T_{i}$ is the member's transformation matrix, which correlates the member's local degrees of freedom to the system's global degrees of freedom; $R_{i}$ is the member's rotation matrix, which rotates the direction of the local degrees of freedom to the global directions; and $k_{i}$ is the member's stiffness matrix in a rank of $6 \times 6$ (Logan, 2007).

\subsection{Matrix analysis of the condensed general equation}

Based on the proposed condensation method discussed in Section 2.2, we are now going to present the end- to -end solution to find the response of the condensed general equation in Eq. (7), which gives the dynamic responses of a system equipped with friction dampers. The main concern of our model is that we consider four independent degrees for each frictional damper. In this way, we can stabilize each node by defining two axials (i.e., a vertical and a rotational degree of freedom). Moreover, the total number of DOFs of the structure is divided into master and slave ones, and the general equation is only solved for the master DOFs. Figure 2 illustrates the conceptual diagram of the proposed approach. To analyze a structure, we first need to set the initial set of parameters such as the number of stories, section area of an element, node coordination matrix, the element coordination matrix, and finally the earthquake records as an external force. After the mentioned parameters are entered, the data process will be now started. In this step the necessary data would be extracted in order to form the condensed general equation. Then, the stiffness matrix and its partitions are calculated based on Eqs. (10) and (11), respectively. Now the general equation of the system can be formed using Eq. (7). To solve a general equation, we use a the Newmark- $\beta$ method. Although the method is discussed in many textbooks in structural dynamics (Chopra, 1995), a brief description of this method as specialized for a nonlinear force deformation model is provided here. The Newmark- $\beta$ method is based on the solution of an incremental form of general equation. Two approaches are presented, i.e., displacement-based and acceleration based. Since using a damper causes the structural response to be maintained in a linear area, we are using Newmark's method, which assumes a linear acceleration over a small time interval, $\Delta t$.

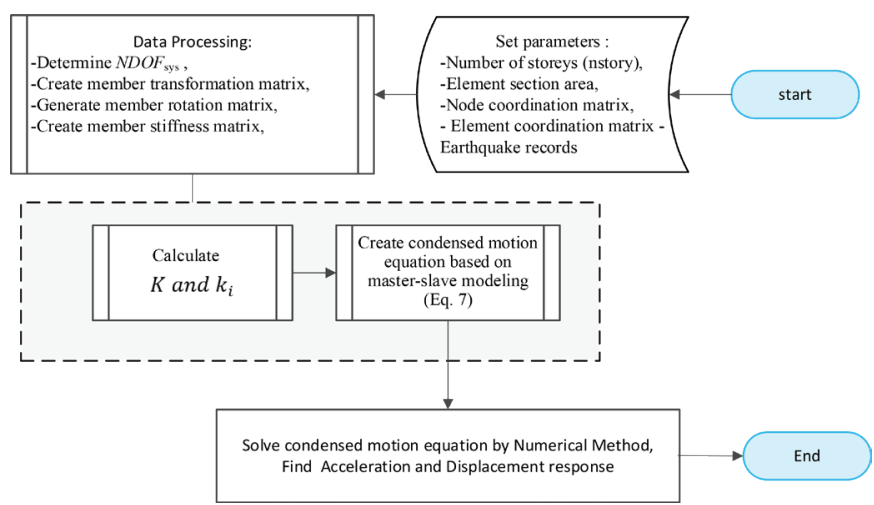

Fig. 2 Conceptual diagram of the proposed matrix analysis method

Assuming a certain specific variation for the acceleration within the time interval the incremental displacement, velocity, and acceleration can be written as

$$
\begin{gathered}
\boldsymbol{M}^{*} \ddot{x}_{i}+\boldsymbol{C} \dot{x}_{i}+\boldsymbol{K}^{*} x_{i}=f_{i} \\
\boldsymbol{M}^{*} \ddot{x}_{i+1}+\boldsymbol{C} \dot{x}_{i+1}+\boldsymbol{K}^{*} x_{i+1}=f_{i+1} \\
\dot{x}_{i+1}=\dot{x}_{i}+[(1-\gamma) \Delta t] \ddot{x}_{i}+(\gamma \Delta t) \ddot{x}_{i+1} \\
x_{i+1}=x_{i}+\Delta t \dot{x}_{i}+\left[\left(\frac{1}{2}-\beta\right) \Delta t^{2} \ddot{x}_{i}\right]+\left(\beta \Delta t^{2}\right) \ddot{x}_{i+1}
\end{gathered}
$$

$x_{i}$ : displacement at moment $i ; \dot{x}_{i+1}$ : displacement at moment $i+1 ; \dot{x}_{i}$ : velocity at moment $i ; \dot{x}_{i+1}$ : velocity at moment $i+1 ; \ddot{x}_{i}$ : acceleration at moment $i ; \ddot{x}_{i+l}$ : acceleration at moment $i+1$. $\boldsymbol{M}^{*}$ : reduced mass matrix; $\boldsymbol{K}^{*}$ : reduced stiffness matrix; $\boldsymbol{C}$ : damping matrix; and $\beta$ is Newmark's constant; $\gamma=1 / 2, \beta=1 / 6$ for the linear acceleration method.

In order to preserve the Newmark- $\beta$ method's stability, the critical time step, $N_{0}$, is defined as Eq. (13):

$$
N_{0}=t . \Delta t, \quad \frac{\Delta t}{T_{f}} \leq \frac{1}{\pi \sqrt{2}} \frac{1}{\sqrt{\gamma-2 \beta}}
$$

is the largest natural period of the structure. 
In order to verify the accuracy of the condensed general equation, the Runge-Kutta numerical method is used (Butcher, 1996). In fact, we are going to show the structural response in both non-condensed and condensed general equations. The former is solved by Newmark- $\beta$ method, and the latter is solved by the Runge-Kutta method. The most commonly used constants in using a fourth order Runge-Kutta method give the following series of formulas:

$$
\begin{gathered}
\ddot{x}_{i+1}=\ddot{x}_{i}+\frac{1}{6}\left(k_{1}+2 k_{2}+2 k_{3}+k_{4}\right), \\
k_{1}=h \cdot f\left(x_{i}, \ddot{x}_{i}\right), \\
k_{2}=h \cdot f\left(x_{i}+\frac{1}{6} \cdot h, \ddot{x}_{i}+\frac{1}{2} k_{1}\right), \\
k_{3}=h . f\left(x_{i}+\frac{1}{2} \cdot h, \ddot{x}_{i}+\frac{1}{2} k_{2}\right), \\
k_{4}=h . f\left(x_{i}+h, \ddot{x}_{i}+k_{3}\right)
\end{gathered}
$$

\section{RESULTS AND DISCUSSION}

\subsection{Four- storey building with a friction damper}

To assess the performance of the proposed method, we first investigated the behavior of the system in detail. Figure 3 shows the analyzed frame under the proposed method. Based on our method, the total DOFs of the system is divided into 4 master DOFs and 32 slave DOFs. A general equation is formed that is based on the master DOFs. Then, we used the procedure for the matrix analysis method as explained in Figure 2 to find the displacement response of some DOFs by the proposed method, including a condensed general equation based on the master-slave

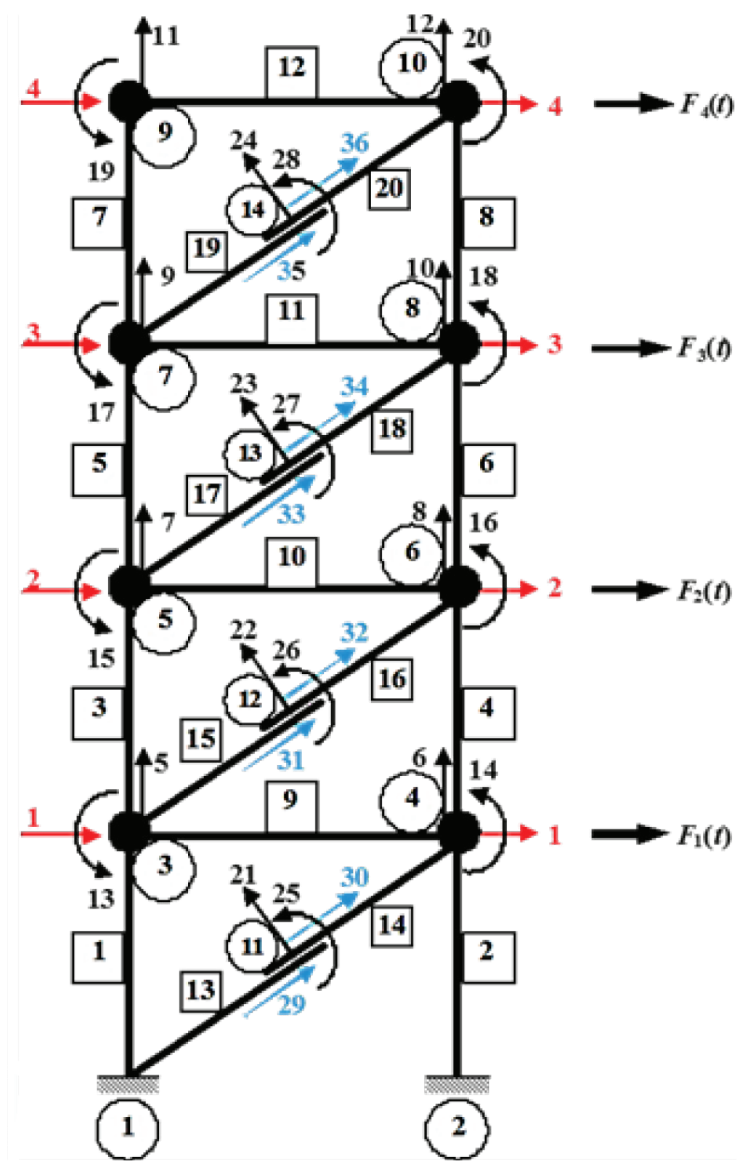

Fig. 3 Analyzed four-storey friction-damped structure frame under the proposed matrix analysis method theory. In order to compare the results, the response of each storey is first investigated with both methods, i.e., the traditional non-condensed general equation and the proposed condensed general equation.

The simulation results of both methods is illustrated in Figure 4. The external force is an impulse function with a duration of $8 \mathrm{~s}$ and $\Delta t=0.005$ s. The Runge-Kutta method is used to solve the non-condensed general equation, and the Newmark method is used for the proposed condensed general equation. The simulations are carried out in Mathcad software. Figure 4 demonstrated that the response of both methods is close to each other. This is despite the fact that in the proposed method, the computational cost and time of the situation would be reduced. This is because the actions from the presented method are based on a reduced number of degrees of freedom, instead of the total number of equilibrium equations and non-zero stiffness terms. So, the order of complexity is limited by the number of operations for the formation of the local matrices of one element. Also, in the Newmark method we can solve second-order ODEs directly without having to convert them into a state-space which is necessary for Runge-Kutta methods. This means fewer DOFs; hence a lower computational cost, when compared to the Runge-Kutta methods.

The structure is then analyzed with relation to Tabas and ChiChi earthquakes. Figure 5 shows the records for the above mentioned earthquakes.

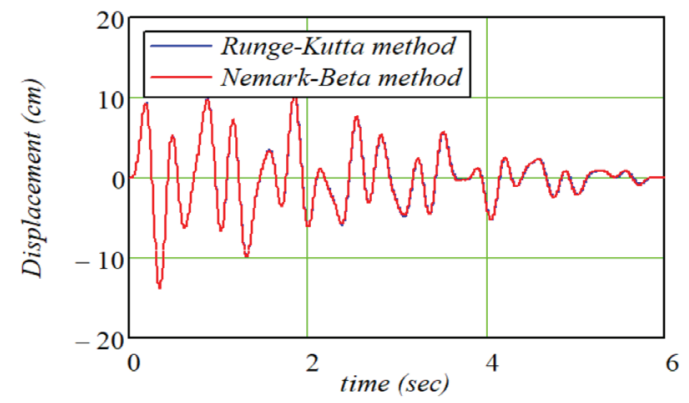

(a) displacement at Storey \# 1

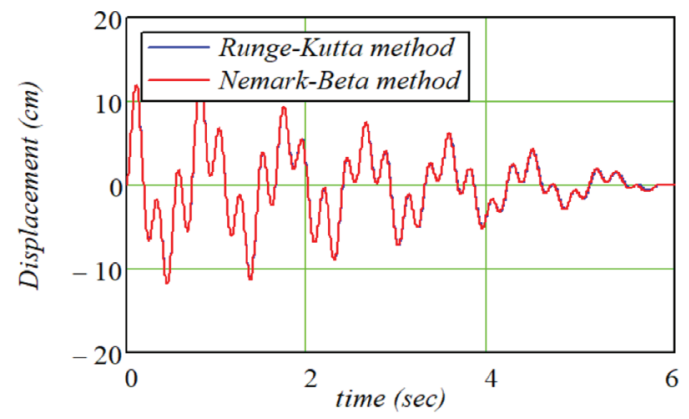

(b) displacement at Storey \# 2

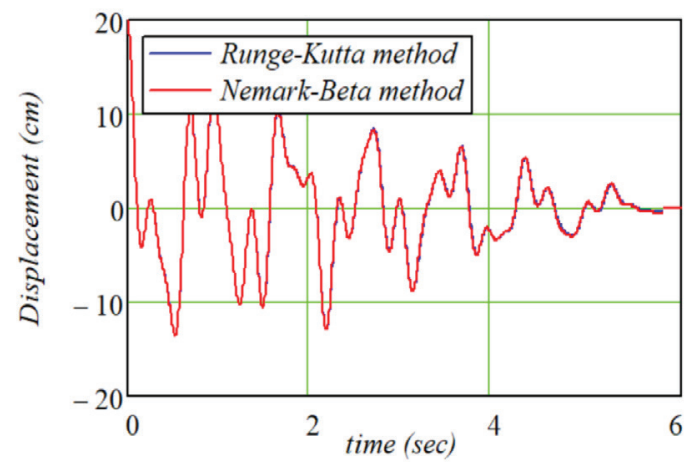

(c) displacement at Storey \# 3

Fig. 4 Comparison of the condensed general equation by the Newmark method and the non-condensed one by the Runge-Kutta method under an impulse function 


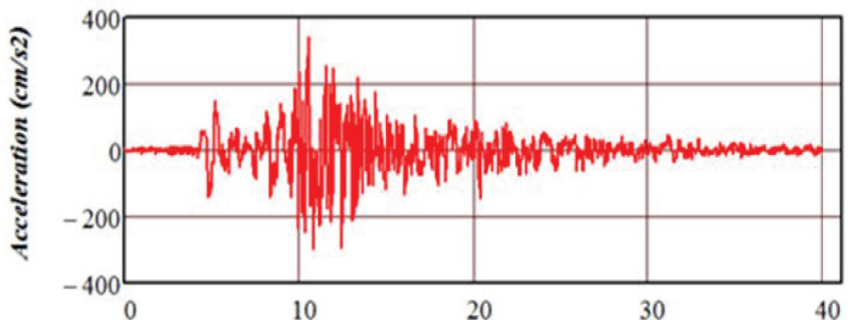

(a) Tabas

Fig. 5 Earthquake records

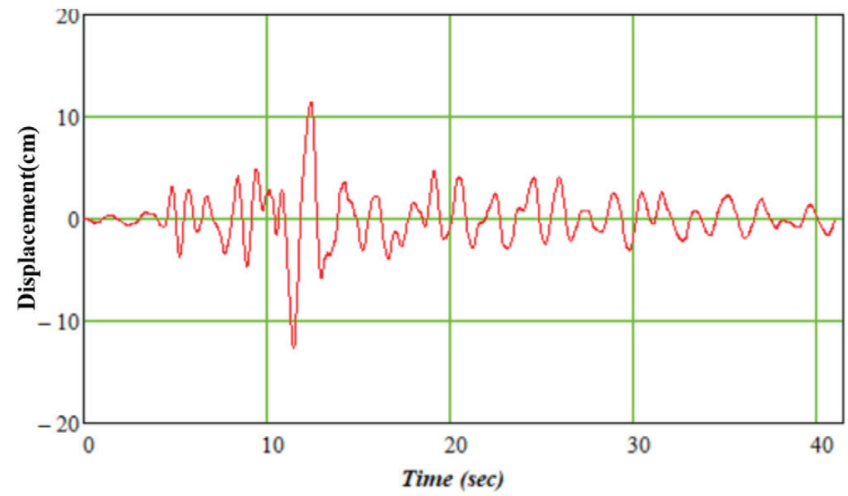

(a) Displacement

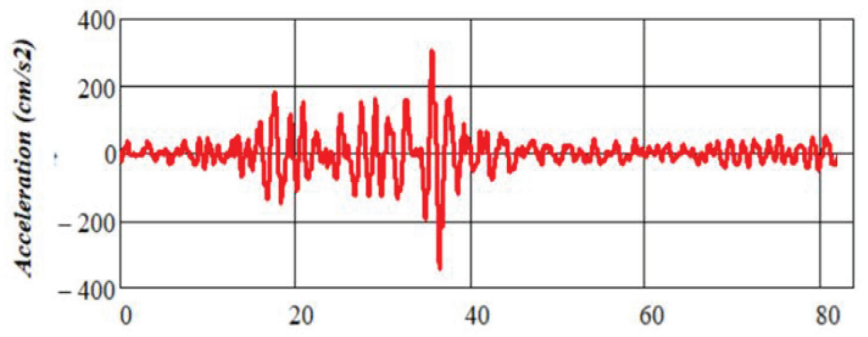

(b) Chi-Chi

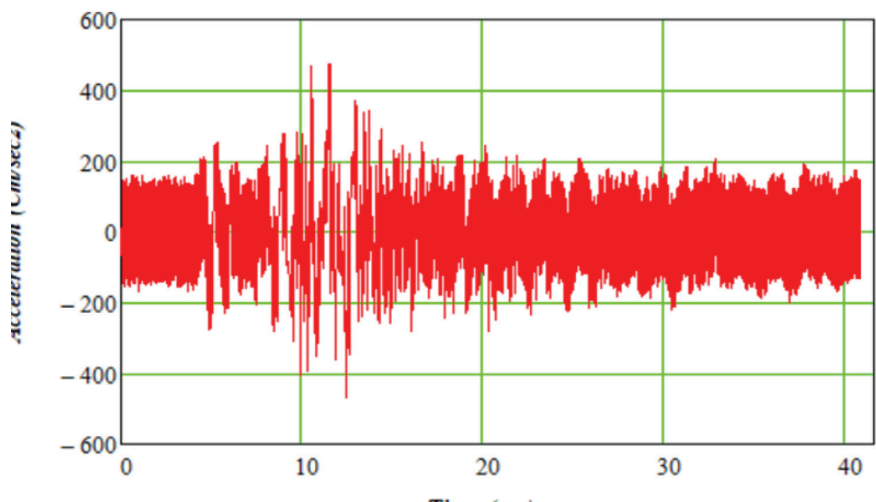

(b) Acceleration

Time (sec)

Fig. 6 Response of the four-storey friction-damped structure using the proposed method, under Tabas earthquake

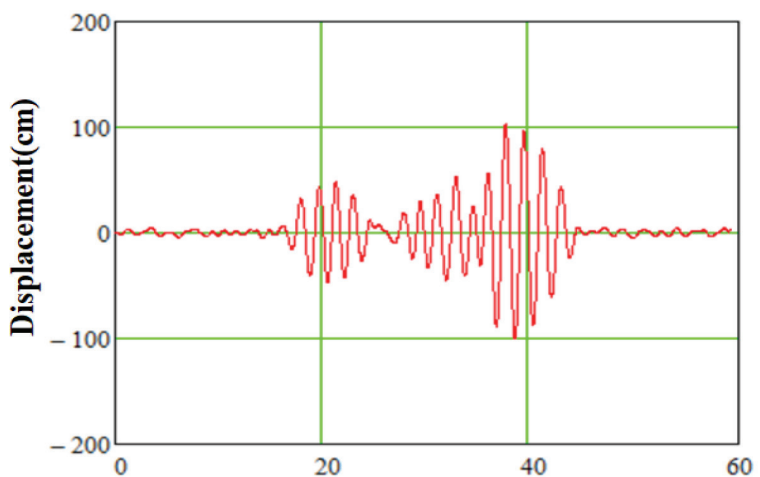

(a) Displacement

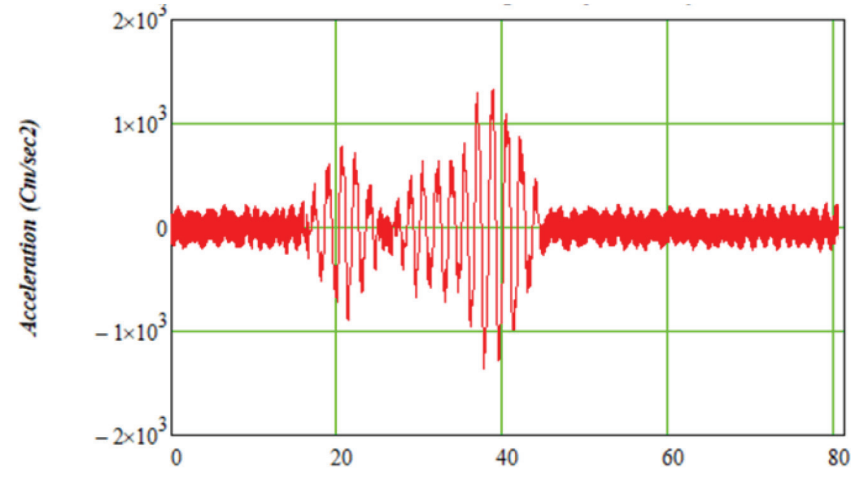

(b) Acceleration

Fig. 7 Response of the four-storey friction-damped structure using the proposed method, under the Chi-Chi earthquake

The displacement and acceleration responses of the four -storey frame analyzed under the proposed algorithm and the Tabas earthquake are illustrated in Figure 6. In a similar way, Figure 7 shows the response of the four -storey building under the Chi-chi earthquake.

In order to verify the method presented, the frame of Figure 3 is analyzed by other FEM software such as OpenSees. The results of the comparison are shown on Figure 8. Also, the first 4 natural frequencies according to both methods were determined to be $6.258,17.766$, 30.173 , and 47.424 .

\subsection{Six and ten- storey building with a friction damper}

For the second scenario, we investigated a two-bay six storey and a ten-storey friction-damped building in which one friction damper is used on each floor. The analyzed structures under the proposed

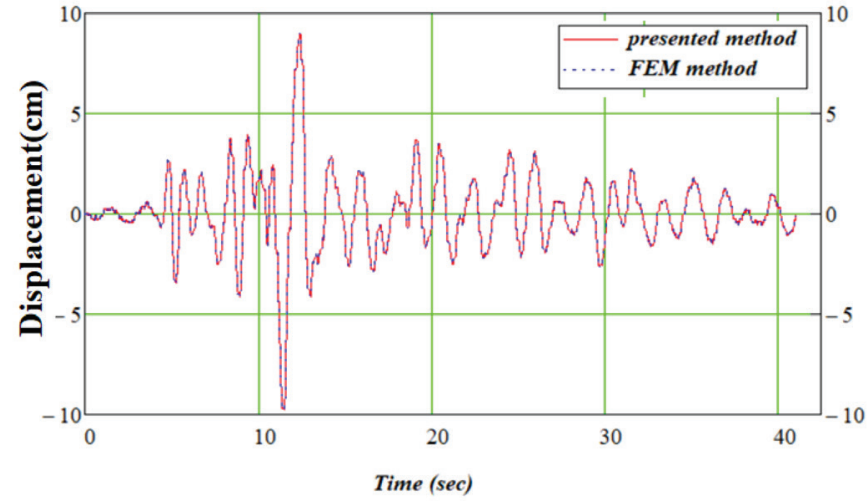

Figure 8 Comparison of the four-storey-friction damped structure's displacement according to different methods under the Tabas earthquake 


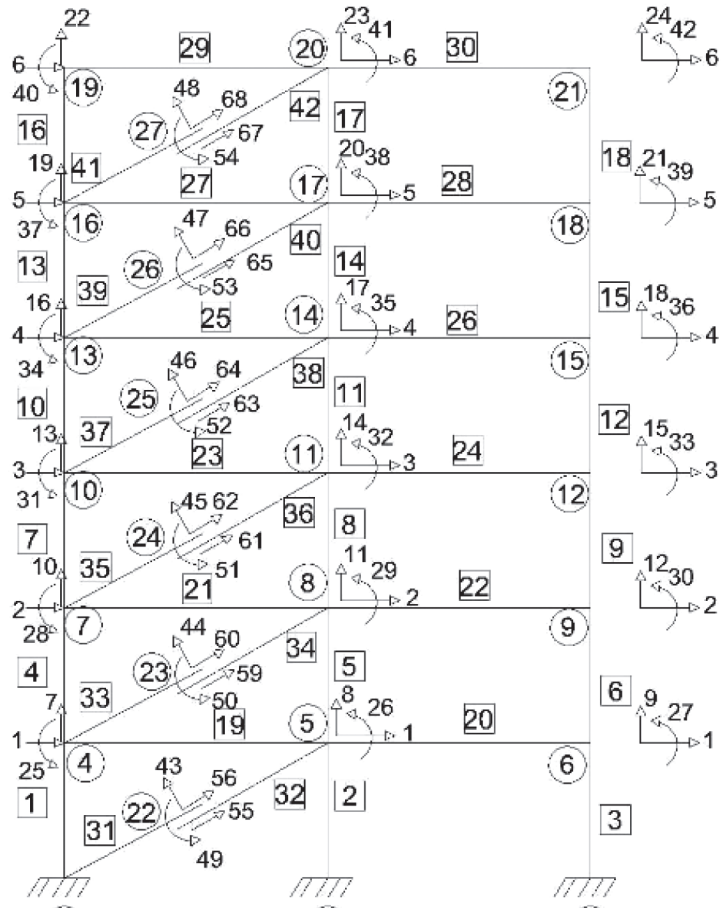

(1)

(a) two-bay six storey friction- damped structure

Fig. 9 Frame Specification

method are shown in Figure 9. The degrees of freedom for a corner joint and an internal friction joint are three and four respectively. The acceleration and displacement responses are shown in Figure 10.

For a further investigation we have analyzed 6, 7, 10, and 14 storey, both 1-bay and 2-bay, equipped structures with friction dampers

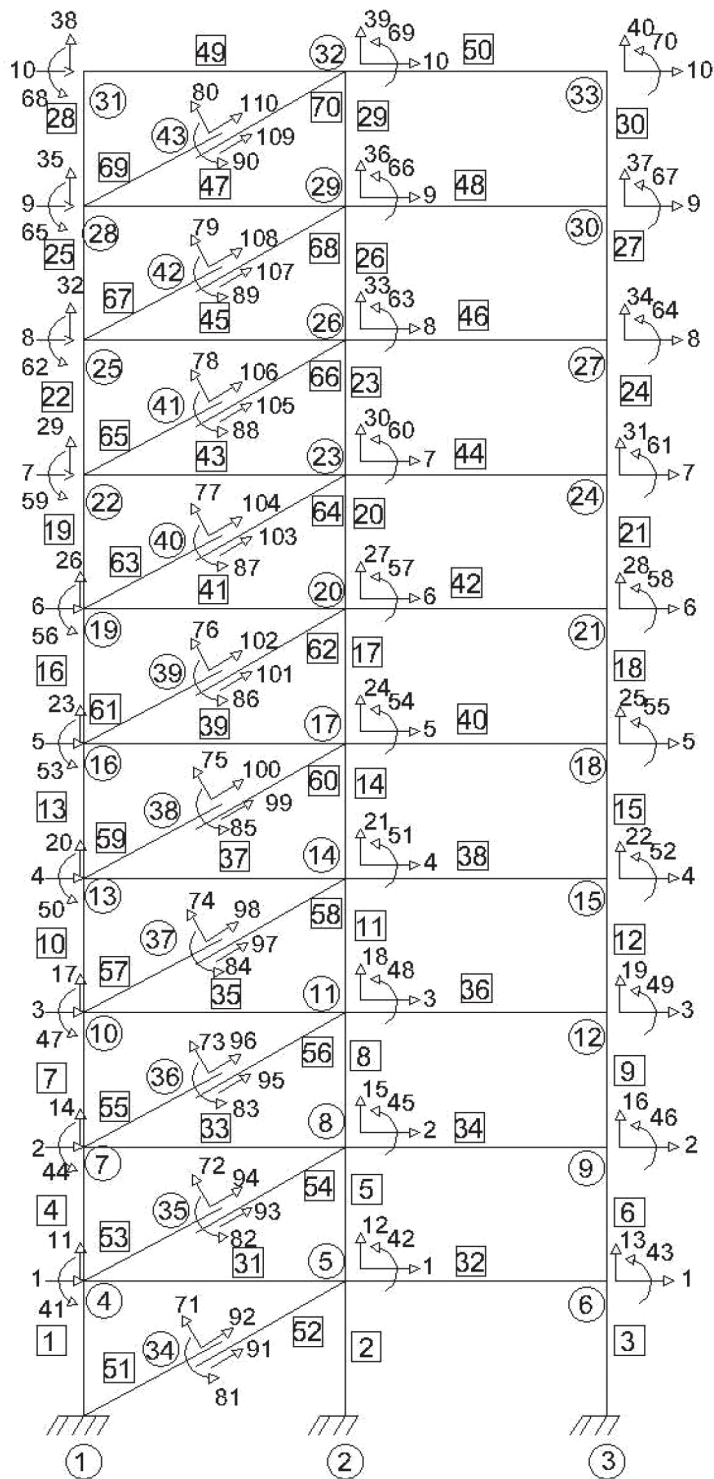

(b) two-bay ten storey friction- damped structure

(see Figure 11). As we expected, the proposed method can be exploited for any structure with different numbers of stories. The results show that analyzing the structures using the proposed method are in a good agreement with traditional software. The performance of the proposed algorithm can be proved, and it can be effective for estimat-

Tab. 1 Maximum acceleration and displacement of four-storey bending frame structure under different earthquakes

\begin{tabular}{|c|c|c|c|c|c|c|c|}
\hline \multirow{2}{*}{ Earthquake } & \multirow{2}{*}{ Parameter } & \multicolumn{2}{|c|}{ Traditional FEM Software } & \multicolumn{2}{|c|}{ Proposed Method } & \multicolumn{2}{|c|}{ Deviation $(\%)$} \\
\hline & & 1-Bay & 2-Bay & 1-Bay & 2-Bay & 1-Bay & 2-Bay \\
\hline \multirow{2}{*}{$\begin{array}{l}\text { Manjil, (1990), } \\
\text { PGA (cm/s/s): } 28.21\end{array}$} & Acceleration $\left(\mathrm{m} / \mathrm{s}^{2}\right)$ & 10.90 & 12.68 & 11.06 & 12.79 & 1.4 & 0.86 \\
\hline & Displacement $(\mathrm{cm})$ & 29.202 & 31.89 & 29.66 & 32.01 & 1.5 & 0.37 \\
\hline \multirow{2}{*}{$\begin{array}{l}\text { Kobe, }(1995) \\
\text { PGA }(\mathrm{cm} / \mathrm{s} / \mathrm{s}): 603.61\end{array}$} & Acceleration $\left(\mathrm{m} / \mathrm{s}^{2}\right)$ & 7.82 & 10.89 & 7.89 & 10.92 & 0.8 & 0.27 \\
\hline & Displacement $(\mathrm{cm})$ & 17.86 & 19.76 & 18.03 & 19.8 & 0.94 & 0.20 \\
\hline \multirow{2}{*}{$\begin{array}{l}\text { El-Centro, (1940), } \\
\text { PGA (cm/s/s): } 210.14\end{array}$} & Acceleration $\left(\mathrm{m} / \mathrm{s}^{2}\right)$ & 14.38 & 10.63 & 14.49 & 10.79 & 0.75 & 1.48 \\
\hline & Displacement $(\mathrm{cm})$ & 29.87 & 23.96 & 30.02 & 24.1 & 0.5 & 0.58 \\
\hline
\end{tabular}




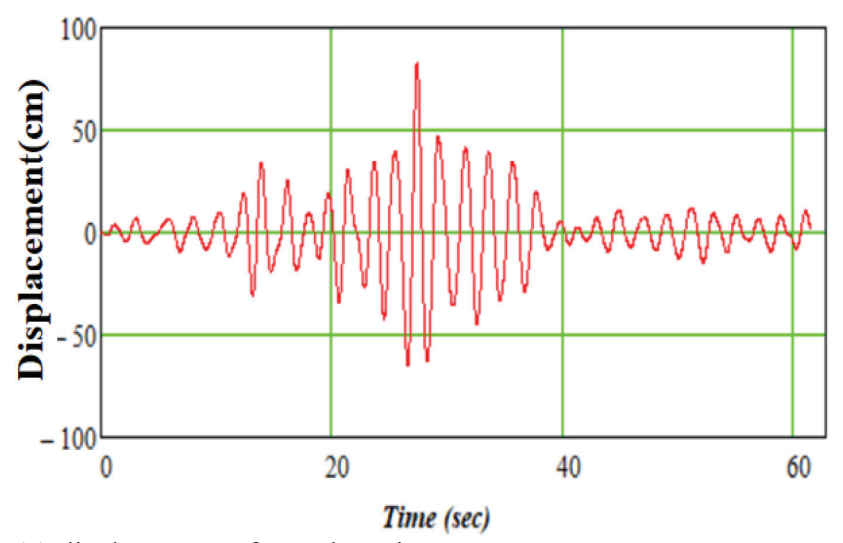

(a) displacement of two-bay six - storey

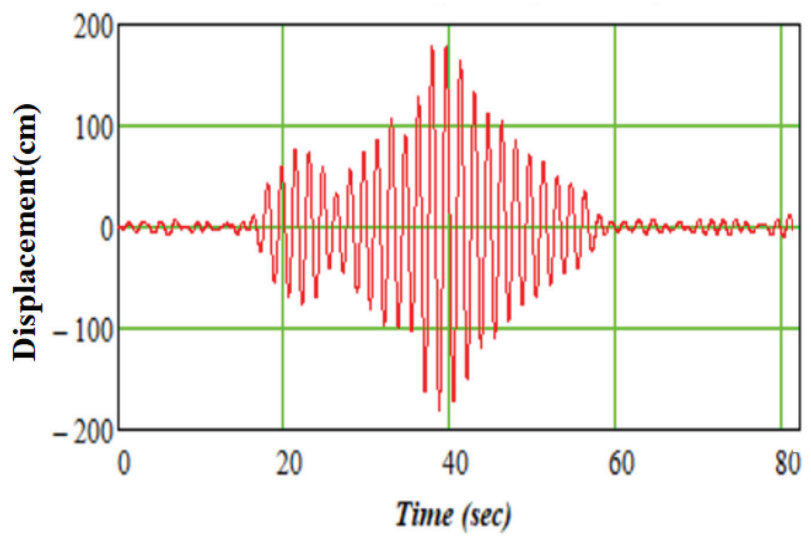

(c) displacement of two-bay ten storey

Fig. 10 Time responses under the Chichi earthquake

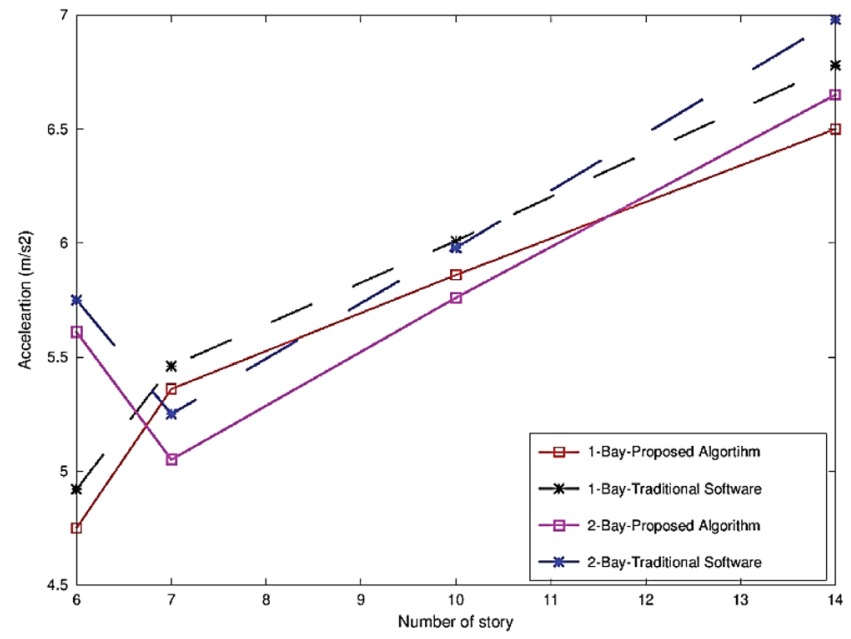

Fig. 11 Comparison of the peak acceleration of various structures with the proposed and traditional methods

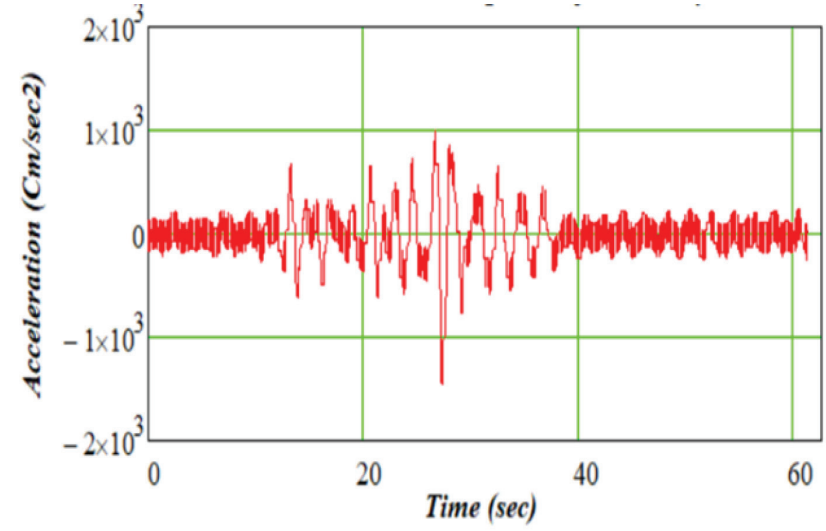

(b) acceleration of two-bay six -storey

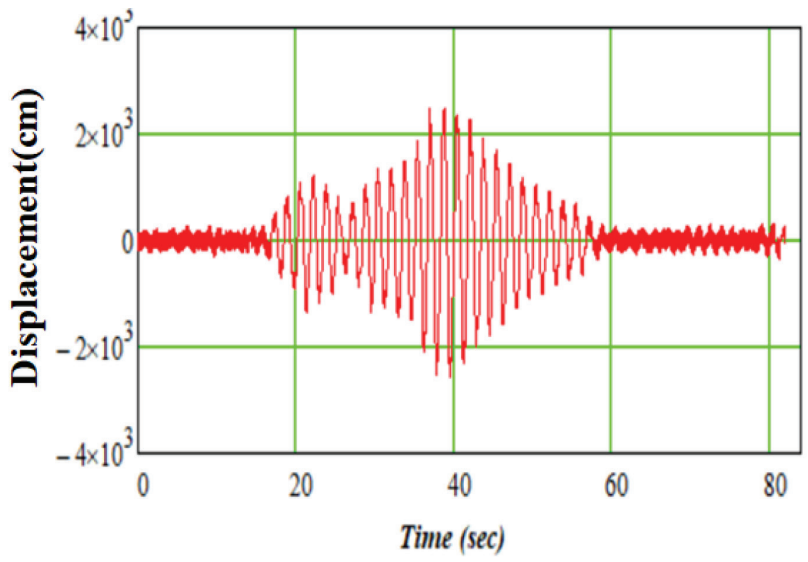

(d) acceleration of two-bay ten storey

ing the acceleration parameters of various structures. The small differences between the two methods occur due to the output sampling time interval used for them.

\section{CONCLUSION}

This work presented the matrix analysis method in order to analyze the behavior of friction- damped structures. In the proposed method, the total DOFs are divided into master and slaves, and the frictional joints are modeled by 4 DOFs. In this way, we extracted the condensed general equation in which only dynamic loading was occurred on the master DOFs, and the slaves act as an static DOFs and could be presented based on the responses of the master DOFs. Then, end -to -end solution was designed based on the matrix analysis and numerical methods. Both the proposed method and the traditional non-condensed methods were investigated, and the results of the solution by the Runge-Kutta and Newmark methods were compared. Also, the proposed method was implemented for 4, 6, 10, and 14 storey 1-bay and 2-bay structures under different earthquake records. A comparison of the results of the proposed method and traditional FEM software showed minimum and maximum deviations of $0.2 \%$ and $1.5 \%$, respectively. Another notable aspect of the presented method was its lower complexity order in such a way that by increasing the number of stories, it was about $20 \%$ lower than that of the traditional method. 


\section{REFERENCES}

Armali, M. - Damerji, H.- Hallal, J.- Fakih, M. (2019) Effectiveness of friction dampers on the seismic behavior of high rise building VS shear wall system, Engineering Reports Wiley online library, Vol.1, No. 5, pp. 1-14, https://doi.org/10.1002/eng2.12075.

Butcher, J. C. (1996) A history of Runge Kutta method, Applied Numerical Mathematics, Vol. 20, No. 3, pp. 247-260, https://doi. org/10.1016/0168-9274(95)00108-5.

Caudana, Q. H.- Petkovski M. (2018) Optimum performance of structural control with friction dampers, Journal of Engineering Structures, Elsevier, Vol. 172, pp. 154-162.

Chopra, A.K. (1995) Dynamics of structures: Theory and Applications to Earthquake Engineering, Prentice-Hall, N J, USA.

Daryl Logan, L., (2007) A first course in the finite element method, Rahul Print O Pack, Dehli-20. ISBN:81-315-0217-1.

Dadkhah, H. - Noruzvand, M. (2017) Optimal Response-Related Weighting Matrices to Control Semi-Active Base Isolation Systems, Slovak Journal of Civil Engineering, Vol. 25, No. 2, pp. 24-32. DOI: https://doi.org/10.1515/sjce-2017-0009

Hosseini, S. P. - Shabakhty, N. (2017) Effect of the improved Pall friction damper on the seismic response of steel frames, Engineering, Technology \& Applied Science Research, Vol. 7, No. 4, pp.1833-1837.

Jarrahi, H. - Asadi, A. - Khatibinia, M. - Etedali, S. (2020) Optimal design of rotational friction dampers for improving seismic performance of inelastic structures, Journal of Building Engineering, Elsevier, Vol. 27, pp. 1-17, https://doi.org/10.1016/j. jobe.2019.100960

Khanlari, K. - Esmaeilzad, A. (2018) Dynamic condensation of non-classically damped structures using the method of Maclaurin expansion of the frequency response function in Laplace domain, Journal of Sound and Vibration, Vol. 426, No. 9, pp.111-128, DOI: 10.1016/j.jsv.2018.04.016.

Králik, J. (2010). Deterministic and probabilistic analysis of damping device resistance under impact loads from nuclear fuel container drop, Slovak Journal of Civil Engineering, 18(1), 1-16. doi: https://doi.org/10.2478/v10189-010-0004-6.

Miguel, F. - Lopez, R. H. (2016) Simultaneous optimization of force and placement of friction dampers under seismic loading, Engineering Optimization Journal, Vol. 48, No. 4, pp.582-602, DOI: 10.1080/0305215X.2015.1025774.
Nabid, N. - Hajirasouliha, I. - Petkovski, M. (2017) A practical method for optimum seismic design of friction wall dampers, Earthquake Spectra, Vol. 33, No. 3, pp.1033-1052

Nabid, N. - Hajirasouli, I. (2019) Adaptive low computational cost optimization method for performance-based seismic design of friction dampers, Engineering Structures, Vol. 198, No. 1, https://doi.org/10.1016/j.engstruct.2019.109549.

Nabid, N. - Hajirasouli, I. (2019) Simplified Method for Optimal Design of Friction damper Slip Loads by Considering Near-Field and Far-Field Ground Motions, Journal of earthquake engineering, pp. 1-25, DOI: https://doi.org/10.1080/13632469.2019.1605 $\underline{316 .}$.

Ontiveros-Pérez, S. P. - Fleck, F. M., (2017) A new assessment in the simultaneous optimization of friction dampers in plane and spatial civil structures, Hindawi Mathematical Problems in Engineering, DOI:10.1155/2017/6040986, pp.1-18.

Ounis, H. (2013) Parameters influencing the response of a base-isolated building. Slovak Journal of Civil Engineering, Vol. 21, No. 3, pp. 31-42. DOI: https://doi.org/10.2478/sjce-2013-0014.

Pall, A. S. (1996) Friction-dampers for seismic control of buildings, A Canadian experience, WCEE, 11th World Conference on Earthquake Engineering, Vol. 497, pp. 1-8. ISBN: 0080428223.

Pall, A. - Pall, R. T. (2004) Performance-based design using pall friction dampers-an economical design solution, 13th World Conference on Earthquake Engineering, Vancouver, BC, Canada. No. 1955, pp. 1-15.

Sanghai, S. - Pawade, P. Y. (2014) Effect of the position and number of friction dampers on the seismic response of frame. International Journal of Earth Science and Engineering, Vol. 7, No. 5, pp. 1854-1859.

Shaw, S. W., (1986) On the dynamic response of a system with dry friction, Journal of Sound and Vibration, Vol. 108, No. 2, pp.305325, DOI: 10.1016/S0022-460X(86)80058-X.

Soong, T. T. - Dargush, G. F. (1997) Passive Energy Dissipation Systems in Structural Engineering, John Wiley \& Sons, London, UK.

Wu, B. - Zhang, J. - Williams, M. S. - Ou, J. (2005) Hysteretic behavior of improved Pall-typed frictional dampers, Engineering Structures, Vol. 27, No. 8, pp.1258-1267, DOI: https://doi. org.10.1016/j.engstruct.2005.03.010. 